\title{
$\triangle$ NICHE AND PERFORMANCE: THE MODERATING ROLE OF NETWORK EMBEDDEDNESS
}

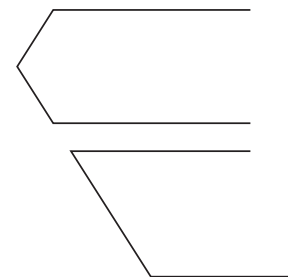

\author{
ANN ECHOLS* and WENPIN TSAI \\ Smeal College of Business Administration, Pennsylvania State University, University \\ Park, Pennsylvania, U.S.A.
}

\begin{abstract}
What is the relationship between niche and performance? We identify two types of niche positions-product niche and process niche-defined by the extent to which a firm offers distinctive products and has distinctive operational processes, respectively. We argue that the effect of each niche on firm performance is contingent upon network embeddedness-the extent to which a firm is involved in a network of interconnected inter-firm relationships. Using data covering the period 1995-98 pertaining to venture capital firms and their holdings in initial public offerings (IPOs), we show that both product niche and process niche interact with network embeddedness to determine firm performance. Our findings suggest that the extent to which a firm offers distinctive products or processes will be more positively associated with firm performance when network embeddedness is high. Copyright (c) 2004 John Wiley \& Sons, Ltd.
\end{abstract}

\begin{abstract}
A key to understanding inter-firm competition is the concept of niche. A niche represents a firm's distinctiveness relative to other players in the competitive arena. As such, a niche describes not only a firm's competitive environment, but also how it competes with others (Carroll, 1985). A niche allows a firm to establish differences by offering a product or set of products that few, if any, other firms offer (Porter, 1980; Stuart, 1998), or by doing business using operational processes that few, if any, other firms practice (Baum and Oliver, 1996; Carroll, 1984, 1985). ${ }^{1}$ Firms in a niche
\end{abstract}

Keywords: network embeddedness; product niche; process niche; venture capital

${ }^{*}$ Correspondence to: Ann Echols, Smeal College of Business Administration, Pennsylvania State University, 403 Business Administration Building, University Park, PA 16801, U.S.A.

E-mail: aiel@psu.edu

${ }^{1}$ Obviously, a firm could maintain a number of different niches, including both a product and process niche, but for the purposes of this paper our study is limited to the concept of firms in a single niche-either a product or process niche. (niche-firms) thus create value by way of offering products or practicing processes that differ in some significant way from those of rivals.

The concept of niche has attracted considerable interest in management research. Population ecologists have examined properties of a firm's niche (Hannan and Freeman, 1977; McPherson, 1983) and the impact of a niche position on competitive dynamics. For example, in a study of the worldwide semiconductor industry, Podolny, Stuart, and Hannan (1996) have shown that niche-firms have enhanced firm survival rates. Strategic management scholars have also identified the niche position as a way of competing in the marketplace. For example, in studying strategic groups, Harrigan (1985) investigated the heterogeneity of strategic positions among firms and emphasized the value of holding a distinctive position in an industry. Drawing extensively from industrial organization economics, Porter $(1980,1996)$ has analyzed competitive positioning of firms and argued that niche-firms can justify charging higher prices. A 
niche-firm gains economic profit because it works in a relatively uncontested market. Being in a niche means the firm is not under pressure to reduce prices, because the more distinctive the firm's products or processes, the less competition the firm faces.

Although the convergence of organizational ecology and strategic management research has highlighted the importance of the niche concept in understanding different aspects of competitive dynamics, it has not clarified the performance effect of a firm's niche. Several scholars have identified advantages as well as disadvantages that accrue to niche-firms (e.g., Carroll, 1984). For example, a niche may have negative consequences when a market dries up, rendering a firm's products or practices obsolete (Liles, 1977). In this study, we test the performance implications of a firm's niche, where a niche is a continuum of relative distinctiveness describing what products the firm offers or how the firm does business.

To understand how niche is associated with different performance outcomes, we use a contingency perspective and argue that the effect of niche on performance is contingent upon network structure. The network structure describing with whom firms interact is an important contingency factor, because firms do not make key decisions about what product(s) to offer and how to do business in a social vacuum without considering other firms (Burt, 1992; Granovetter, 1985). Thus, the niche-performance relationship can be better understood by simultaneously examining a firm's niche and network structure. By considering a firm's network structure, we are able to specifically answer our research question: Under what conditions does the distinctiveness of a firm's niche provide performance benefit to the firm?

The central tenet of our argument is that how well a niche-firm performs is contingent upon the extent to which it is embedded in an inter-firm network. To examine this, we focused on the U.S. venture capital industry as our research setting. The U.S. venture capital industry provides an ideal setting because this is an industry with high competitive pressure motivating many firms to be niche players. In addition, this is an industry in which firms frequently form networks of inter-firm working relationships. By simultaneously investigating a firm's niche position and network embeddedness in the venture capital industry, our paper advances a theory of competitive positioning in strategic management and provides a more refined understanding of how venture capital firms compete.

\section{THEORY AND HYPOTHESES}

A niche implies a 'way of earning a living' (Elton, 1927: 63-64): an explanation from animal ecology, whereby niches are identified by looking at the key attributes of earning a living in terms of what the animal eats and how it preys (Ricklefs, 1979). Similarly, in the business context, a firm's niche can be studied by investigating how a firm differs from its rivals in terms of what products it offers and how it does business (e.g., the operational processes it chooses to practice) (Day, 1981; Porter, 1996). As such, a niche is defined by the extent to which a firm's product offering or operational processes are unlike what rivals offer or practice, respectively. In this research, we focus on two kinds of niches or ways a firm 'earns its living' distinctively: its product offerings or operational processes.

\section{Product niche}

The concept of product niche describes a firm's competitive position based on an analysis of the competitive intensity surrounding what products the firm offers. A firm in a product niche position offers products that-because they differ considerably in ways that are economically meaningful from those of its rivals - create value. By offering a product or set of products that differ from those of competitors, a firm can reduce its competitive pressures, increasing its likelihood of gaining a competitive advantage (Porter, 1980). There are many examples of distinctive product offerings. In the automobile industry, Audi TT, an all-wheeldrive coupe, is a distinctive product, since very few automobile manufacturers offer a vehicle that combines a sports-look coupe body with all-wheeldrive capability. In the vision care industry, Johnson \& Johnson's 1-day ACUVUE is a distinctive product, since it is the only UV-blocking daily disposable lens in the marketplace. These examples are of single products, which are easy to explain; yet multi-product firms can also create a niche by offering a distinctive product mix identified by aggregating the distinctiveness of individual product offerings to the firm level. By examining the relative distinctiveness of each product in a firm's 
product portfolio and aggregating this information, we can determine the firm's overall product niche.

\section{Process niche}

The concept of process niche describes a firm's competitive position based on an analysis of how the firm operates its business. A firm in a process niche position engages in business operations that-because they differ considerably in ways that are economically meaningful from those of its rivals - create value. A process niche rests on the distinctiveness of the firm's operating knowhow or ways of practicing business. Whether or not it offers distinctive products, a process nichefirm practices a different way of operating its business, including managing the processes related to its value chain activities in an innovative way (Chatterjee, 1998). For example, some online retail stores are classified as process niche-firms when they provide a distinctive online ordering process that allows customers to perform real-time inventory checking and shipment tracking in a convenient, reliable, and timely fashion. Although offering the same name-brand products as competitors do, these online stores differentiate themselves with a distinctive operational process that attracts customers. The distinctive operational process has resulted in a proprietary business model that shows the importance of a process niche. The idea of process niche is also illustrated in a recent article by Markides (1998), showing how a small Danish bank called Lan \& Spar altered its operational processes to employ a unique, real-time system, enabling it to conduct business differently and, hence, become a niche-firm.

\section{Network embeddedness as a moderator of the niche-performance relationship}

How does a firm's niche position affect its performance? The above discussions on product niche and process niche describe a firm's decisions concerning what to offer and how to operate. However, a firm's performance is not simply a function of these decisions. Instead, these decisions and the firm's resulting performance are contingent upon another important factor: the firm's social structure that describes who connects to whom in the firm's network. A firm's competitive position, including decisions regarding whether or not to be a product or process niche-firm, is not formed in a social vacuum. When making decisions about what to offer and how to operate, a firm must, at the same time, take into account the social context in which it interacts with other firms. Through collaborations with other firms in the industry, a firm involves itself in an inter-firm network that contains useful information and resource flows. The structure of such a network is a critical factor in determining the success of any firm's niche position.

Research in economic sociology has highlighted the importance of social networks in economic actions (Granovetter, 1985; Coleman, 1990). The 'performance of firms can be more fully understood by examining the network of relationships in which they are embedded' (Gulati, Nohria, and Zaheer, 2000: 203). Networks of inter-firm relationships provide channels for sharing valuable information and resources. A firm can use its network channels to search for advice and gain access to key resources needed to deal with its competitive challenges. As many scholars have argued, network relationships are an important aspect of the social capital that determines a firm's ability to create value or to achieve economic goals (e.g., Coleman, 1990; Tsai and Ghoshal, 1998; Tsai, 2000). Drawing on social network theory, we use the concept of network embeddedness to examine the impact of a niche-firm's relationships on its ability to perform well.

Network embeddedness describes the structure of a firm's relationship with other firms - specifically, the extent to which a firm is connected to other firms and how interconnected those firms are, in turn, to each other (Granovetter, 1992; Nahapiet and Ghoshal, 1998). Network embeddedness means the extent to which a firm is surrounded by other firms in such a way that its network structure is redundant or not. At one extreme, high network embeddedness means that a firm belongs to a dense network among other firms, many of which are tightly connected with each other. In such a dense network, firms tend to know each other well through recurring interactions and interconnected ties that engender familiarity and trust (Gulati, 1995; Gulati et al., 2000). At the other extreme, low network embeddedness means that a firm belongs to a sparse network in which few of its contacts are not connected to each other. In such a sparse network, firms may instrumentally work with a variety of other firms that are 
not fully aware of each other's working relationships. Figure 1 provides an illustration of the concept of network embeddedness based on inter-firm relationships in the venture capital industry. As shown in this figure, Crosspoint Venture Partners has a redundant network (e.g., high embeddedness) because it is connected to firms that work with each other. In contrast, New Enterprise Associates has a non-redundant network (e.g., low embeddedness) because it is connected to firms that do not work with each other. Given that a firm's network structure significantly affects the firm's business opportunities and performance (Burt, 1992; Granovetter, 1985; Powell, 1990; Tsai, 2001; Uzzi, 1996), a firm has to pay close attention to the structure of its network, optimizing not just a single relationship, but also the firm's entire network of relationships (Dyer and Nobeoka, 2000; Gulati et al., 2000).

We examine how network embeddedness moderates the performance effects of product and process niche. To accomplish this objective, we integrate the network embeddedness concept with a contingency approach (which suggests two or more predictor variables with interactive effects on the value of the criterion variable; e.g., Aiken and West, 1991). Thus, we analyze how network embeddedness and niche position interact to affect firm performance.

We argue that network embeddedness brings benefits to both product and process nichesthough in two different ways. While firms in a product niche require fine-grained product or market information, firms in a process niche require protection of process knowledge, all else held equal. Because firms in a product niche and firms in a process niche require different kinds of information and knowledge to succeed, we discuss how network embeddedness moderates each niche, accordingly.

\section{Interaction between product niche and network embeddedness}

We argue that the impact of product niche on firm performance is contingent upon the extent to which the firm is embedded in a network within which it can obtain specific information needed to develop and market its products. The more distinctive a firm's product offerings, the more it requires specific market information to succeed. Product niche-firms usually need specific information regarding the detailed profiles of certain customers, the specifications of certain product parts, and the quality of certain suppliers. Obtaining exact information is critical to firms that need to stay abreast of complex and often rapidly changing information. These firms have little if any tolerance for information noise (i.e., information that is unreliable or unsubstantiated). To reduce information noise, a firm can make use of a highly embedded network, since such networks provide multiple and repetitive sources of information, enabling constant reassessment of information accuracy. As Rowley, Behrens, and Krackhardt have argued, 'the ability to triangulate among multiple sources allows firms to evaluate the information obtained and gain a richer understanding' (Rowley, Behrens, and Krackhardt, 2000: 375).

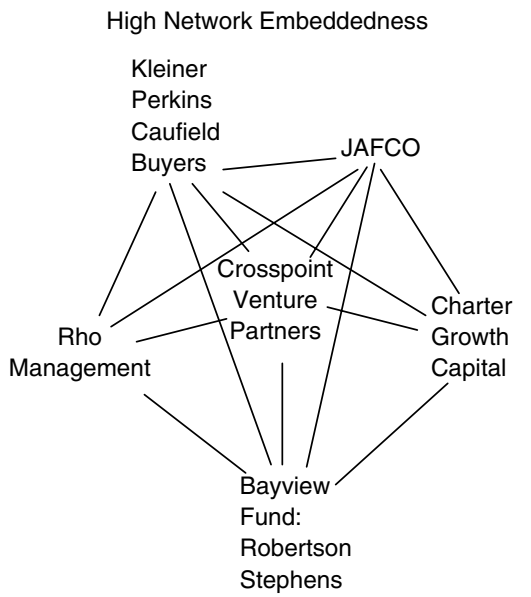

Low Network Embeddedness

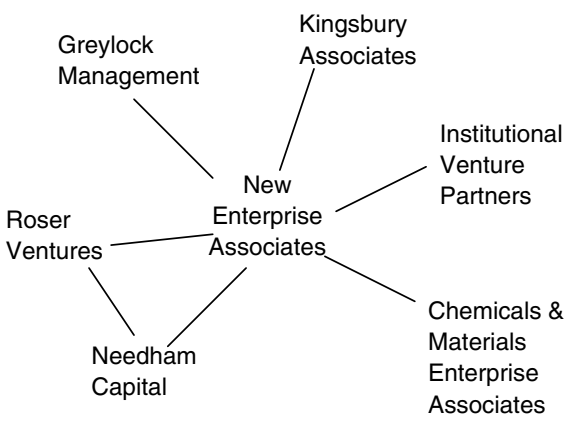

Figure 1. Network embeddedness 
High network embeddedness describes a network with enduring, interconnected ties that are useful sources of detailed and fine-grained information (Gulati, 1998; Uzzi, 1996). Such information can be transferred within a network in which more opportunities exist to clarify possible ambiguities and abstractions (Jones et al., 1998). Actors strongly tied in a network tend to have developed a relation-specific heuristic for processing complex and fine-grained information (Hansen, 1999).

Thus, when network embeddedness is high, a product niche is likely to be positively associated with firm performance. This is because intensive interactions in an embedded network allow the niche player to perform better by gaining and acting on fine-grained, reliable information essential for developing and marketing distinctive or even unique products. In contrast, when network embeddedness is low, the product niche-performance relationship is likely to be less positive or even negative. This is because the less connected structure of a low-embeddedness network may offer coarse, unreliable information-information that may distract the firm from operating effectively in its niche position, thus resulting in poor performance.

Hypothesis 1: The interaction between product niche and network embeddedness has a positive impact on firm performance (i.e., the extent to which a firm offers distinctive products will be more positively associated with firm performance when network embeddedness is high).

\section{Interaction between process niche and network embeddedness}

The impact of process niche on firm performance is contingent upon the extent to which the firm is embedded in a network that safeguards the process knowledge needed to effectively secure its ways of doing business. A process niche-firm adopts distinctive ways of doing business and has special operational knowledge. The more a firm relies on distinctive processes to compete with other firms, the more the firm needs to protect its special operational knowledge to succeed. Compared to firms in a product niche, firms in a process niche have distinctive processes but may not have distinctive products. These firms will emphasize securing the distinctive process knowledge they already have rather than emphasize gathering fine-grained product or market information.

A firm in a process niche has distinctive knowledge that it considers top secret. Protecting this knowledge from other companies is essential to the firm's success. Research on secret disclosure has suggested secret flows in a 'clique communication model' that involves only interconnected ties among clique members (Steele, 1989). Because the interconnected ties of a highly embedded network can provide multiple channels to facilitate communications within partnerships and prevent revealing special knowledge to unwanted parties, a process niche-firm benefits from a highly embedded network structure. Such a firm is better off maintaining a highly embedded network in which the firms with whom it connects are also tightly connected to each other. Given that distinctive knowledge can influence the processes and outcomes of a firm's operations, a firm will share such knowledge only with trusted others.

High network embeddedness promotes the development of trust (e.g., Krackhardt, 1992; Nelson, 1989). A highly embedded network permits actors to know one another, alleviates appropriation concerns, and allows actors to consider one another trustworthy. Actors who are highly interconnected are likely to develop a shared understanding of behavioral norms within their social system and influence one another to conform to such norms (Coleman, Katz, and Menzel, 1966). The presence of such behavioral norms encourages firms in an embedded network to rely on each other for discretion and security when dealing with special know-how in their partnerships.

In sum, the relationship between process niche and firm performance is likely to be contingent upon the level of network embeddedness. When network embeddedness is high, a process niche is likely to result in high firm performance. This is because interconnected ties provide such a firm with the kind of highly reliable and trustworthy partnerships needed to protect and advance its special knowledge. In contrast, when network embeddedness is low, the process niche-performance relationship is likely to be less positive or even negative as it is difficult to safeguard distinctive knowledge with partners that are not tightly connected. Even though a firm may be willing to trust others in a low-embeddedness network, communication problems are likely to be rife; the lack of multiple channels for communications requires a 
firm to expend significant extra effort, time, and resources to clarify the details of its special operations when working with other firms. Therefore:

Hypothesis 2: The interaction between process niche and network embeddedness has a positive impact on firm performance (i.e., the extent to which a firm has distinctive operational processes will be more positively associated with firm performance when network embeddedness is high).

\section{METHODS}

\section{The U.S. venture capital industry}

The empirical setting of this research is the U.S. venture capital industry (see Lerner, 1994a, for a history of this industry). Venture capital firms raise funds and pool investors' money to purchase equity primarily in private start-up companies. By taking a start-up through its initial public offering (IPO: the event whereby a firm places its stock for public trade for the first time), venture capital firms can generate substantial investment returns on the open market (Gompers and Lerner, 1999). Without IPO investments, venture capital firms are severely constrained both in realizing gains (Huntsman and Hoban, 1980; Tyebjee and Bruno, 1984a, 1984b) and in retaining an investor pool (Black and Gilson, 1999; Freeman, 1999).

When guiding a start-up toward its IPO, a venture capital firm, especially one sitting on the start-up's board of directors, can significantly influence the company's business operations and managerial decisions. Venture capital firms can also add value to start-ups through offering industry-specific expertise, such as knowledge about and connections with suppliers, distributors, and customers (MacMillan, Kulow, and Khoylian, 1989; see also Fried and Hisrich, 1995). Venture capital firms can also take care of different needs associated with the developmental stages of a startup's life (e.g., Carter and Van Auken, 1994; Gorman and Sahlman, 1989; Ruhnka and Young, 1987, 1991).

Although venture capital firms compete with each other in IPO investments, they also collaborate with each other through co-investment: one venture capital firm takes the lead by creating a syndicate using multiple venture capital firms' funds to co-invest in a start-up firm (Lerner, 1994b). Venture capital firms create syndicates not only to increase the amount of money provided to a start-up (Steier and Greenwood, 1995), but to share tasks associated with selecting, managing, and advising start-ups. Venture capital firms within the same syndicate tend to interact with each other to find the best way to increase the value of their common investment. A venture capital firm may have more than one fund and each fund may be involved with several investments simultaneously, enabling it to be a member of many syndicates. In this way, the venture capital firm maintains multiple inter-firm relationships with its co-investors as it strives to increase its relevant expertise and capabilities (Gompers and Lerner, 1999). In addition to a network of co-investment relationships, venture capital firms also maintain relationships with service providers in other industries to meet the startup's needs as they arise (e.g., relationships with consulting, auditing, law, and investment banking firms).

\section{Sample and data collection}

We selected our sample of U.S. venture capital firms based on two criteria. First, we selected venture capital firms that were autonomous in offering private equity financing to start-up enterprises for the purpose of earning high rates of return. By autonomous, we mean independently managed firms that function at arm's length from their funding sources. Thus, our sample includes corporate subsidiaries engaged in providing private equity such as St. Paul Venture Capital, Inc., a selfsustaining unit that makes investment decisions separately from the operations of its parent, St. Paul Fire and Marine Insurance Company. Our sample does not include corporate-directed development capital, such as Hallmark Cards' Development Capital Division or Microsoft's Investment Division, both of which were established for the purpose of satisfying diverse corporate needs rather than simply investing for high rates of financial return.

Second, we selected venture capital firms with influence over start-ups in which they invested. The venture capital firms we selected had required as a condition for receiving venture capital funding that the start-up either allow them a board seat or grant at least one board seat to at least one of the syndicate partners effective as of the time the 
start-up held its IPO. By way of board representation, venture capitalists monitor the start-up and help it to reach the performance goals needed for it to achieve a successful IPO (Barry et al., 1990; see also Jain, 2001). There can be no doubt that venture capital firms can significantly influence the management of any company in which they invest by placing representatives on its board of directors. Therefore, we assume that the venture capital firms selected for our sample exercised such board influence, thereby contributing significantly to the success of their IPO investments.

Our research model uses a temporal sequence: Time ${ }_{1}$ from January 1, 1995, through December 31, 1996; and Time 2 from January 1, 1997, through December 31, 1998. We measured our independent variables - product niche, process niche, and network embeddedness - during Time ${ }_{1}$. We regressed these variables on firm performance measured during Time $_{2}$. This temporal sequence allows us to see the effects of our independent variables on our dependent variable, but not vice versa. To identify which venture capital firms were associated with which IPOs as well as the attributes of these IPOs, we used multiple archival sources, including Securities Data Company's New Issues data, VentureOne's IPO Reports, Venture Economics' VentureXpert data, and Center for Research in Securities Prices (CRSP) stock price data. We also identified venture capital firms' attributes using Galante's Venture Capital and Private Equity Directories and Pratt's Guides to Venture Capital Sources. We validated data across sources and remedied the few data discrepancies that existed by bringing these inconsistencies to the attention of the publishers who originated the data. In all cases, appropriate representatives working for the data publishing companies conceded the errors or omissions, and clarifications were made on a case-by-case basis. We also made several phone calls to venture capital firms to fill in missing data.

Our final sample includes 80 venture capital firms active in both Time 1 and Time $_{2}$ that held investments in a total of 369 IPOs. To ensure that the IPOs were comparable, we included only IPOs with firm commitment underwriting arrangements, and excluded unit issues, financial industries (SIC codes 6000-6999), spin-offs, privatizations, foreign tranches, and American Depository Receipts/American Depository Shares, as suggested by Ritter (1991) and Megginson and Weiss (1991).

\section{Measures}

\section{Dependent variable}

Firm performance. We operationalized venture capital firm performance using the number of successful IPOs in each venture capital firm's Time 2 portfolio. ${ }^{2}$ The majority of the profits accrued to venture capital firms are generated by only a few successful IPOs (Black and Gilson, 1999; Gompers, 1994; Huntsman and Hoban, 1980; Lerner, 1994c; Sahlman, 1990). Identifying successful IPOs is critical to understanding a venture capital firm's performance, as these few successful IPOs are considered to be 'home runs' (Schilit, 1991), providing tremendous benefit to venture capital firms. Not only does a venture capital firm's potential to earn high returns increase when its investment can be traded on a public market, but successful IPOs offer valuable non-monetary benefits through image enhancement that attracts further investor and entrepreneur attention (Lerner, 1994c). The most successful IPOs receive intense media hype and attention. Such acclaim often shines a strong light onto the venture capital firms that supported them.

We identify a successful IPO using a buy-andhold strategy as suggested by Ritter (1991): the IPO must have a compounded daily return greater than the return generated by the corresponding daily NASDAQ Composite Index, documented as of the end of each month (where a month is defined as a successive 21-day trading period relative to the IPO offering date), cumulatively, for the IPO's first 12 consecutive months in the aftermarket. ${ }^{3}$ The algorithm we used is mathematically presented in Appendix 1.

\section{Independent variables}

Product niche. A product niche describes the extent to which a firm's product lines differ from those of its competitors. In this research, a venture capital firm's product line is defined by the IPOs in which it invests, where an IPO is defined by

\footnotetext{
${ }^{2}$ We control for the total number of IPOs in venture capital firms' Time $_{2}$ portfolio via the 'exposure' variable in our Poisson regression model.

${ }^{3}$ The first 252-day period is equivalent to an IPO's first year on the market, where a month is defined as a successive 21-day trading period, following Ritter (1991).
}

Strat. Mgmt. J., 26: 219-238 (2005)$$
\text { Strat. Mgm, J, 26: 219-238 (2005) }
$$ 
its primary 3-digit Standard Industrial Classification (SIC) code. ${ }^{4}$ Any two venture capital firms, if not co-investing, are considered to have competing products if their IPOs are in the same 3-digit SIC code. The more a venture capital firm's product portfolio is like the portfolios of other venture capital firms (having many IPOs in the same 3digit SIC code as other firms' IPOs), the less the venture capital firm has a product niche.

We measured a venture capital firm's product niche by first calculating for each focal venture capital firm the proportion of its IPOs sharing the same 3-digit SIC code with the competing IPOs of every other venture capital firm in our sample. Since there are 80 firms in our sample, we compared each focal firm with the other 79 firms. We then subtracted each proportion from 1 to arrive at a distinctiveness score (which ranged from 0 to 1.0). We then aggregated the distinctiveness score of each firm with every other firm in the sample; this measure is the product niche score. The idea of our product niche score calculation is similar to Stuart's (1998) operationalization of niche position. A high product niche score indicates that the venture capital firm's product portfolio was relatively distinctive compared to the product portfolios of other firms. A low product niche score indicates that the venture capital firm is very similar to its competitors in terms of the investment products offered.

Process niche. A process niche captures the extent to which a firm differentiates itself by operating its business using a distinctive process or processes. Venture capital firms operate differently in terms of whether they are involved with investments at different stages. Each specific stage of a start-up's development requires correspondingly specific know-how on the part of the venture capital firm (Carter and Van Auken, 1994; Ruhnka and Young, 1987). For example, a venture capital firm involved in early-stage investing must capitalize on knowledge about product commercialization, setting up a business, and hiring quality managers, as well as targeting and selling to an appropriate market. In contrast, a venture capital firm involved

\footnotetext{
${ }^{4}$ We focus on a 3-digit SIC level instead of a 4-digit SIC level in this research, because there were too many unique industry categories at the 4-digit SIC level, and our dataset contained enough observations for each industry category in order for us to capture overlap among firms.

in later-stage investing must capitalize on knowledge about establishing internal control mechanisms, managing public relations, and expanding the business, which may include finding diversification opportunities. By being involved in certain stages of investment, a venture capital firm creates a profile of its operational knowledge.

Thus, a venture capital firm creates a process niche by signaling to potential customers that it will conduct business in a certain investment stage or set of stages that differ from those of its rivals in ways that create value. Likewise, entrepreneurs look for venture capital firms that have expertise in the investment stage most appropriate to their current requirements. A venture capital firm with expertise in a distinctive set of investment stages has a knowledge profile that enables it to operate differently from other venture capital firms. This is similar to the way firms in the daycare industry differentiate different stages for their operations, as reported by Baum and Oliver (1996). Therefore, using data from Galante's Directories, we applied Baum and Oliver's (1996) niche measure to indicate the extent to which a venture capital firm uses a distinctive set of investment stage knowledge. Appendix 2 shows the computational detail for the process niche measure. A venture capital firm with a high process niche score used processes that were different compared to the processes used by other firms. A venture capital firm with a low process niche score was very similar to its competitors in terms of its operational processes.

Network embeddedness. Based on Burt's (1992) network redundancy measure, we operationalized network embeddedness to represent the interconnectedness of each venture capital firm's contacts within our dataset. Each venture capital firm's network included a set of inter-firm relationships defined by the number of times each firm coinvested in IPOs with partner venture capital firms during Time . $_{\text {. }}$.

Because the network redundancy measure can be biased by network size, we cannot compare it across networks of different sizes, unless we control for network size (Scott, 2000). The collinearity between the redundancy measure and network size (i.e., the larger a focal firm's network, the less likely it is to have a densely embedded network) presents a limitation: we cannot simultaneously include both network redundancy and network size as two separate variables in our model. Instead, we 
divided the network redundancy measure by network size, an appropriate way to deal with this situation as suggested by Pedhazur and Schmelkin (1991).

By dividing network redundancy by network size, the measure results in a very small score. To adjust this measure to a scale comparable to that of other variables, we multiplied it by 100 . The result of this adjustment reflects the proportional redundancy in a focal firm's network. A high measure indicates that a focal firm's network consists of tightly connected others relative to its network size. A low measure indicates that a focal firm's network consists of unconnected or loosely connected others relative to its network size.

\section{Control variables}

We controlled for venture capital firm-level characteristics including firm size, firm age, firm type, focus, proximity to IPO, and competitive intensity. We operationalized firm size as the logarithm of the amount of capital (in millions of dollars) under management associated with each venture capital firm as of the end of Time ${ }_{1}$. We operationalized firm age as the number of years from the founding year to the year 1996. We operationalized firm type by distinguishing between limited partnerships and other organizational forms (e.g., independent subsidiaries of banks, public corporations, or private corporations). We used a dichotomous variable, coding 1 for venture capital firms organized as limited partnerships, and 0 for all others. ${ }^{5}$ We operationalized focus as the number of 3-digit SIC codes in the venture capital firm's Time ${ }_{1}$ portfolio. We operationalized proximity to IPO as the mean distance in statute miles between the zip code associated with each of the venture capital firm's IPO holdings in Time 1 and the zip code associated with its closest office to that IPO. ${ }^{6}$ The closer the venture capital firm is located to its investments, the

\footnotetext{
${ }^{5}$ In this research, we found differences at the 0.05 level of significance between limited partnerships and other venture capital firms in terms of firm age, location, and whether or not they charged fees for their services. We found no evidence that these two types of firms differed in terms of our independent variables: firm size, network size, total number of IPO investments, and number of successful IPOs. Nor did we find evidence that they differed in regard to several other attributes. We included variables reflecting the differences between firm types as controls in additional analyses. These differences did not influence the interaction effects we hypothesized.

${ }^{6}$ We chose to focus on the venture capital firm's closest office to the IPO for the sake of parsimony, since some of the venture

more intense its monitoring of and influence on that investment is likely to be (Lerner, 1995). We operationalized competitive intensity by counting the number of venture capital firms located within a 120-mile radius of a focal venture capital firm's main office as of the end of Time ${ }_{1}$, where distance was computed in statute miles between office zip codes. We chose a 120-mile radius based on inferences from Lerner's (1995) findings.

In addition to the above firm-level attributes, we controlled for one investment-level variable: investment size. Investment size may affect performance since larger investments are typically associated with more mature companies, and hence are more likely to be associated with higher stock price performance than smaller investments. We operationalized investment size as the total annual revenues (in millions of dollars) of each venture in which a venture capital firm invested. We aggregated investment size to the venture capital firm level by taking the mean revenue for all investments in each venture capital firm's Time 2 portfolio.

\section{Assessment of content validity}

Content validity refers to the extent to which measures reflect a specific domain of content (Bollen, 1989). Our approach to content validity focuses on qualitative definitions to specify the scope of content coverage that can be achieved by our measures (Hoskisson et al., 1993). We clarify how each of our measures - firm performance, product niche, process niche, and network embeddedness - appropriately reflect its purported content.

The definition of firm performance includes two domains of interest: financial returns and market success. Whereas financial returns are often measured by profitability, such as the return on an investment, market success is often measured by the performance of an existing product, a new product introduction, or an IPO, for example. The domains are interrelated, since a firm with a high level of market success is likely to have increasing financial returns. However, it is possible that a firm with an initially successful product will not sustain high profitability over time; market leadership,

capital firms had up to three branch offices in addition to headquarters, as stated in the Galante's Directory applicable to the year of observation. For all computations of distances between zip codes in this study, we used Bridger Systems' ZIPFind Deluxe 3.0 software program. 
after all, may be ephemeral. To meet content validity, performance measures must seek to address both domains of interest. Our firm performance measure, the number of successful IPOs, appears to emphasize market success. However, several studies on venture capital firms have shown that successful IPOs represent the majority of a venture capital firm's earnings (Huntsman and Hoban, 1980), and more than 60 percent of their profit (Norton and Tenenbaum, 1993). Also, a successful IPO can generate much recognition for a venture capital firm, garnering the attention needed to attract investors to venture capital funds (Lerner, 1994c). As such, the content validity of our firm performance measure rests on the claims and findings about the importance of successful IPOs in the venture capital context.

Product and process niches are defined as the extent to which a firm has a distinctive set of products or processes, respectively. In the venture capital industry, the major product lines for venture capital firms are the IPO investments in different industries, and the major processes are the different investment stages involved (Fried and Hisrich, 1995; Gupta and Sapienza, 1988, 1992). We have satisfactorily covered the product and process niche constructs by measuring the distinctiveness of venture capital firms' IPO investments and investment stages.

The domain of interest with respect to network embeddedness includes the idea of contact redundancy (otherwise known as network interconnectedness). As described in the Methods section, we operationalize network embeddedness using Burt's (1992) network redundancy measure, which takes into account this domain.

\section{Assessment of face validity}

Face validity addresses whether a measure 'on its face' seems like a good translation of the construct of interest. Several scholars have considered face validity a weak form of construct validity, as it requires subjective judgment throughout the research process (Lacity and Jansen, 1994). However, face validity can be improved if it relies on the judgment of a carefully selected panel of experts (Robinson and O'Leary-Kelly, 1998). Thus, in our assessment of face validity, we sought industry experts' assessments regarding our measures' representation of particular constructs. We consulted five experts: a founder/chief executive officer of a venture capital-backed start-up that went through its IPO, two venture capitalists from different top venture capital firms, and two analysts (professionals paid to analyze and report on venture capital activity), each employed by a different organization. We specifically asked each person if the way we measured firm performance, product and process niche, and network embeddedness were legitimate for the venture capital context. All five experts approved and so established the face validity of our measures.

\section{RESULTS}

Table 1 provides descriptive statistics and a correlation matrix for the variables used in this study. Of the 80 venture capital firms in our dataset, 68 percent were limited partnerships and 50 percent were founded after 1980. The mean capital under management reported by the venture capital firms as of the end of Time $_{1}$ was $\$ 573.85$ million. Over both time periods analyzed, the average number of IPOs supported by a venture capital firm was 11.66. Regarding performance, 25 percent of the venture capital firms had one or more successful IPOs in their Time 2 portfolio.

As shown in Table 1, the correlations among our independent variables are low. To further examine potential collinearity among the variables, we calculated variance inflation factors (VIFs) associated with each of the predictors in our model. The value of VIFs ranged from 1.18 to 1.63 , with a mean of 1.30 , suggesting no problem with collinearity.

We also conducted a skewness test and outlier analyses for all of our independent variables, and found that one variable, network embeddedness, presented a distribution that differed from normality (the Kolmogorov-Smirnov $Z$-value was 3.777 , $p=0.000,2$-tailed). The result is not unexpected, given that network embeddedness measured using Burt's (1992) formulation of network redundancy tends to show a skewed distribution. To see the potential impact of skewness, we winsorized the network embeddedness variable at the extremes of 1 percent and 5 percent, and ran our analysis with the variable winsorized and unwinsorized, respectively (Kendall and Stuart, 1979, for the procedures for winsorizing outlier observations). The pattern of our statistical results is the same, whether or not 


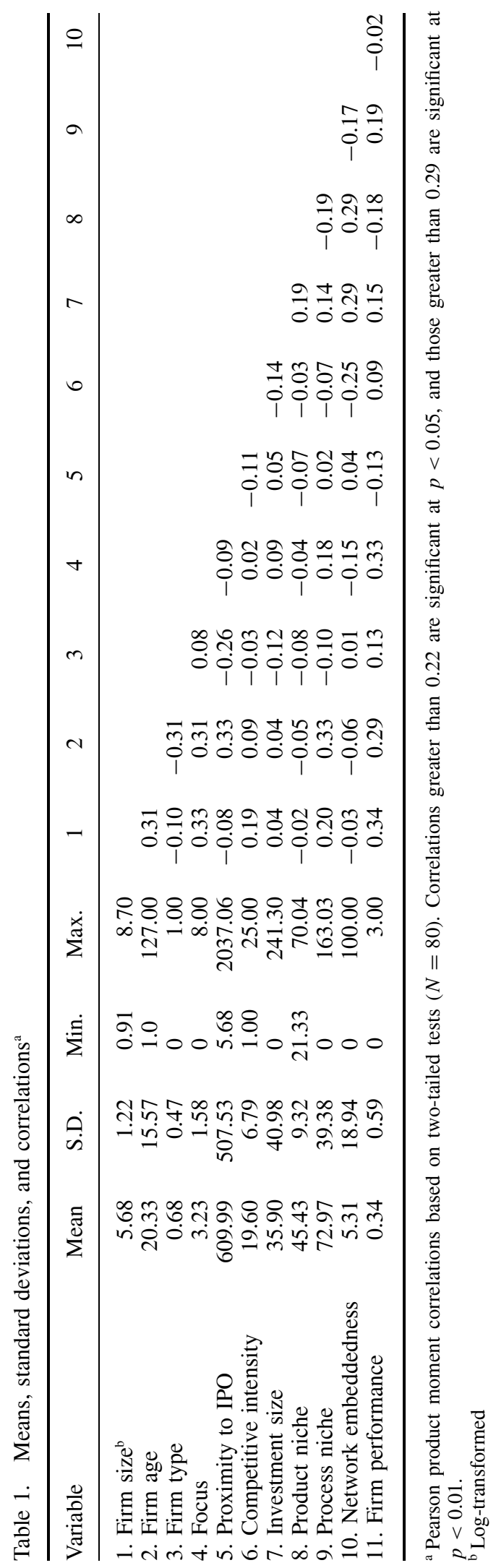


we winsorize the network embeddedness variable. Thus, we report unwinsorized results here.

We relied on Poisson regression to test our hypotheses, because this method is suitable for estimating the number of discrete occurrences of some events (Lindsey, 1995; STATA, 1997), such as the number of successful IPOs in which a venture capital firm invests. We used a chi-square goodness-of-fit test to assess whether our dependent variable fitted a Poisson distribution. The results indicate that we cannot reject the null hypothesis that our dependent variable fits a Poisson distribution $\left(\chi^{2}=1.609 ; p=0.657\right.$; d.f. $\left.=3\right)$.

Table 2 shows the results of our Poisson regression analysis. Four models were estimated. Model 1 is the baseline model including only the control variables. Model 2 adds to the control variables the set of independent variables: product niche, process niche, and network embeddedness. Models 3 and 4 test our two hypotheses regarding the interaction effects between niche and network embeddedness. To test these interaction effects, we mean centered all three independent variables, created a separate multiplicative term between each niche variable and network embeddedness, and entered each multiplicative term into separate models accordingly. As Aiken and West (1991) have suggested, mean centering reduces distortion resulting from a high correlation between the interaction term and its components.

Hypothesis 1 states that the interaction between product niche and high network embeddedness has a positive impact on firm performance. As shown in Model 3 in Table 2, the coefficient of the interaction term between product niche and network embeddedness is positive and statistically significant $(p \leq 0.05)$, suggesting that product niche is more positively associated with firm performance when network embeddedness is high. Model 3 is statistically significant $\left(\chi^{2}=23.79 ; p \leq 0.05\right)$ and shows a substantial improvement over Model 2 (LL-change $=3.73$ ). Hence, we support our hypothesis regarding the positive interaction effect between product niche and network embeddedness on firm performance.

Hypothesis 2 states that the interaction between process niche and high network embeddedness has a positive impact on firm performance. As shown in Model 4 in Table 2, the coefficient of the interaction term between process niche and network embeddedness is positive and statistically significant $(p \leq 0.05)$, suggesting that process niche is

Table 2. Effects of product niche, operational niche, and network embeddedness on firm performance

\begin{tabular}{lcccc}
\hline & Model 1 & Model 2 & Model 3 & Model 4 \\
\hline Intercept & $-7.731^{* *}$ & $-6.061^{*}$ & $-9.331^{* *}$ & $-8.803^{* *}$ \\
Control variables & & & & \\
Firm size & 0.483 & 0.465 & 0.505 & $0.699^{*}$ \\
Firm age & $0.043^{* *}$ & $0.041^{*}$ & $0.045^{*}$ & $0.047^{* *}$ \\
Firm type & $1.636^{+}$ & 1.487 & $2.007^{+}$ & $1.712^{+}$ \\
Focus & -0.106 & -0.046 & -0.038 & -0.148 \\
Proximity to IPO & -0.001 & -0.001 & -0.001 & $-0.002^{+}$ \\
Competitive intensity & 0.019 & 0.032 & 0.055 & 0.071 \\
Investment size & $0.016^{* *}$ & $0.017^{+}$ & $0.029^{*}$ & $0.025^{* *}$ \\
Independent variables & & & & \\
Product niche & & -0.044 & -0.033 & -0.026 \\
Process niche & & 0.001 & 0.002 & 0.011 \\
Network embeddedness & & 0.008 & $-0.635^{*}$ & $0.108^{* *}$ \\
Product niche $\times$ Network embeddedness & & & $0.010^{*}$ & $0.003^{*}$ \\
Process niche $\times$ Network embeddedness & & & & \\
Model statistics & -42.796 & -41.473 & -39.068 & -39.002 \\
Log likelihood & & & 3.728 & 3.794 \\
Change in log likelihood from Model 1 & 16.520 & 19.10 & 23.790 & 23.920 \\
Pseudo- $R^{2}$ & $16.940^{*}$ & $19.580^{*}$ & $24.400^{*}$ & $24.530^{*}$ \\
Model $\chi^{2}$ & 80 & 80 & 80 & 80 \\
N & & & & \\
\hline
\end{tabular}

Two-tailed tests: ${ }^{+} p \leq 0.10 ;{ }^{*} p \leq 0.05 ;{ }^{* *} p \leq 0.01$.

The beta coefficients shown are non-standardized. 
more positively associated with firm performance when network embeddedness is high. Model 4 is statistically significant $\left(\chi^{2}=24.53 ; p \leq 0.05\right)$ and shows a substantial improvement over Model 2 (LL-change $=3.79)$. Hence, we support our hypothesis regarding the positive interaction effect between process niche and network embeddedness on firm performance.

To see the pattern of the interaction effects, we plotted the trend showing the relationship between niche and firm performance at both high and low levels of network embeddedness. We define high- and low-level network embeddedness based on one standard deviation above and below the mean of the network embeddedness variable, respectively. Figures 2 and 3 present the interaction plots, showing that the niche-performance relationship varies depending upon the level of network embeddedness. The plots show that when network embeddedness is high the niche-performance relationship is positive, and when network embeddedness is low the niche-performance relationship is negative. In each figure, the slope of the line that describes the positive relationship

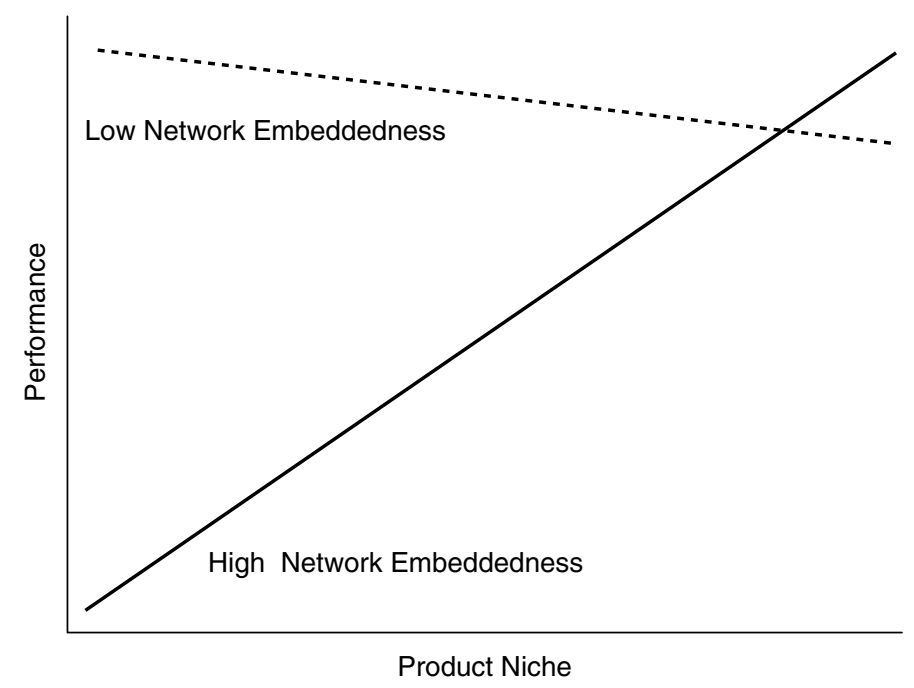

Figure 2. The moderating effect of network embeddedness on the product niche-firm performance relationship

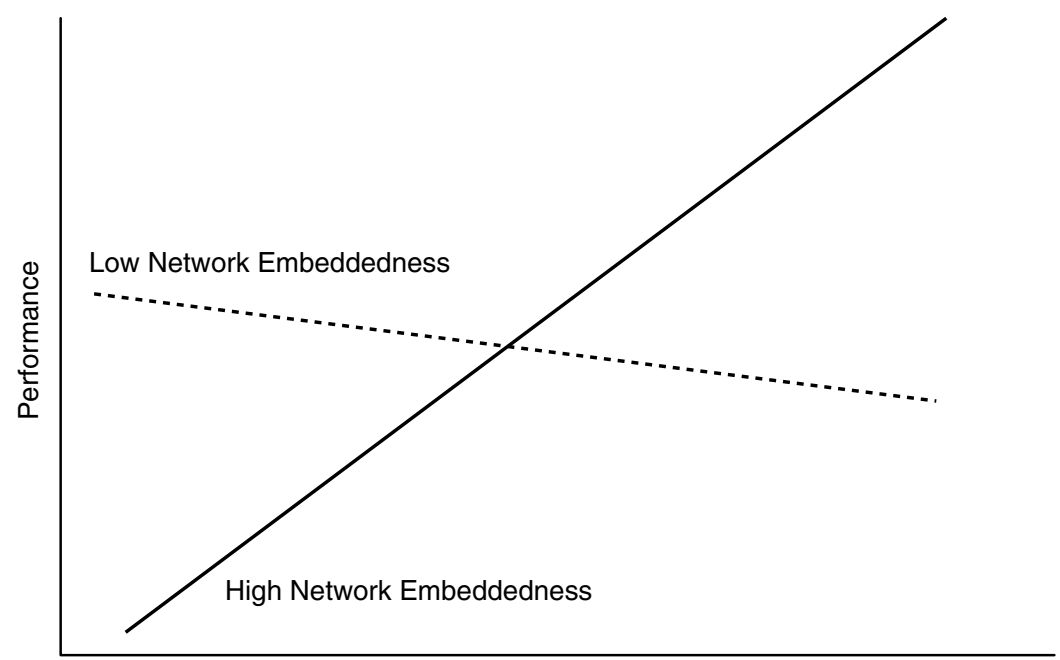

Process Niche

Figure 3. The moderating effect of network embeddedness on the process niche-firm performance relationship 
between niche and performance for firms with high network embeddedness is significantly different from the slope of the line that describes the negative relationship between niche and performance for firms with low network embeddedness.

Since we focused on only the 1995-98 timeframe, readers may think that we only captured the market volatility attributable to the irrational hype associated with the Internet bubble, and failed to capture the subsequent Internet IPO meltdown. To address this, we used a performance benchmark - the NASDAQ Composite Index - to measure daily IPO performance relative to the market's daily performance. Thus, in our study we incorporated the relative strength of each IPO, and not its absolute performance, which is likely to be influenced by overall market activity during a certain period of time.

We also tried to take into account market volatility by controlling for investment uncertainty (measured as whether or not an invested venture made a profit before it went public), and market hype (measured as the extent to which the market price exceeded the prospectus price of the new stock). The statistical significance of our independent variables did not change when these two control variables were included in the Poisson model. Given our concern with limited power due to our small sample, we did not include these controls in our final model.

\section{DISCUSSION}

The purpose of this research is to investigate how a firm's niche may affect its performance under different levels of network embeddedness. We identify two niche types and show that for each the relationship between niche and performance significantly varies when the level of network embeddedness changes. We find that the extent to which a firm is distinctive or in a niche has a more positive impact on its performance when network embeddedness is high. These findings support our hypotheses regarding the network contingency of the niche-performance relationship.

We distinguish between two niche typesproduct and process - based on what products the firm offers, and how the firm operates its business. By identifying two different niche types, our research contributes to a better understanding of ways in which a firm can be distinctive or different from its competitors. Previous research tends to focus on one niche type, mainly product niche, without acknowledging the fact that a firm can be distinctive and gain a competitive advantage in other ways. Studying two niche types provides a more comprehensive understanding of competitive positioning. By identifying different niche types, our research opens new avenues for scholars to examine niche strategies from different viewpoints.

We investigate the niche-performance relationship to understand how firms may obtain a competitive advantage. Findings in previous research (Brush and Chaganti, 1999; Galbraith and Schendel, 1983; Lawless and Anderson, 1996) suggest that the niche-performance relationship is not always straightforward. For example, traditional strategy models of competitive positioning suggest that a firm can benefit by being in a niche (e.g., Harrigan, 1985; Morrison and Roth, 1992; Porter, 1980); yet our research shows that the niche-performance relationship is not always positive. Negative or positive performance outcomes may accrue depending upon the distinctiveness of the product offering (e.g., extent of its product niche) or operational processes practiced (e.g., extent of its process niche) coupled with the extent to which each firm's inter-firm network is structurally embedded.

\section{Implications for management research}

That niche and network embeddedness interact to explain performance is a significant finding; competitive positioning research could, therefore, benefit from investigating the network structure of inter-firm cooperative relationships. Most studies on competitive positioning are silent about the importance of inter-firm cooperative relationships, even though firms tend to compete and cooperate with each other at the same time. Given that competition and cooperation tend to be flip sides of the same coin (Tsai, 2002), the extent to which a blending between competitive positioning and cooperative strategies takes place should receive more attention in future strategic management research.

Further, when examining the economic benefits of competitive positioning, researchers should pay close attention to how a network of relationships among firms functions. The network of firms is social in nature. And when we refer to 
the social context we are in fact pointing to the social characteristics of firm networks. Although prior research has highlighted the importance of competitive positioning in the marketplace, very few studies have discussed the role of competitive positioning in a social context. A firm does not do everything alone, nor does it make decisions about what to do without considering what other firms are doing. Given that firm behavior and performance are shaped by social relationships (Granovetter, 1985), a firm's competitive positioning cannot be meaningfully analyzed without considering its relational position in a social context. Our research suggests that scholars can better understand how firms gain a competitive advantage by investigating the structure of inter-firm networks characterizing the social context.

Our study shows how the structure of a firm's inter-firm network may serve as a contingency factor affecting the benefits of a firm's niche position. The social network literature has documented both the pros and cons of maintaining embedded vs. sparse network structures. Some scholars have shown how a sparse network structure leads to better economic outcomes than does a dense network structure, due to the sparse network's ability to provide flexibility, autonomy, control, and access (Burt, 1992). Other studies have shown how a dense network structure contributes to better economic outcomes than does a sparse network structure, due to the dense network's ability to facilitate the sharing of in-depth knowledge and tacit knowhow, as well as safeguard customized exchanges (Podolny, 1994; Uzzi, 1996, 1997). Studies separately considering the benefits of either sparse or dense network structures are prevalent in the literature, yet these studies are inconclusive in determining which type of network structure is better or worse for firms. One reason for a lack of consistent findings, we believe, is that firms differ greatly relative to each other in terms of their product lines, and the way they operate. Such differences have not yet been considered in the network literature. Yet, these differences imply that firms pursuing different strategies (whether or not they strategically opt to pursue a product or process niche) need different levels of network embeddedness to succeed. Both types of structure may be beneficial depending upon the firm's strategy, as suggested by the literature setting forth the advantages and disadvantages of sparse vs. highly embedded networks (Baker and Obstfeld, 1999; Burt,
1992; Coleman, 1990, 1994; Granovetter, 1973; Lin, 1999; Podolny and Baron, 1997). However, without considering firm-level differences in terms of major strategic decisions, research on inter-firm networks is incomplete. In our study, we simultaneously consider relative firm-level differences and relative network structure, showing the value of both low embeddedness and high embeddedness, as one way to resolve the debate.

Our research relied on both the management and finance literatures to inform us about venture capital activities. Both the management and finance disciplines seek to better understand venture capital as an industry, the impact of venture capital on IPO performance, and, more specifically, the operational processes of venture capital firms. Our research offers a preliminary step toward understanding the venture capital industry. Although we focus on the effect of venture capital firms' niche on performance, our results provide an impetus for future research to more fully explore the processes related to various investment activities and competitive-cooperative dynamics in the venture capital industry. Future research might focus on exploring the processes whereby a venture capital firm selects its investment portfolio, structures its networks, and allocates its resources (time, expertise, and money). Many opportunities exist for collaboration between research in management and finance, especially when it comes to furthering our understanding of venture capital firms' activities.

\section{Implications for management practice}

Understanding the determinants of firm performance is the most important managerial issue for every firm, including venture capital firms. Our findings provide insight as to how venture capital firms might gain performance benefits by being in a niche position. Although not hypothesized, our results showed that the relationship between niche position and firm performance can be either positive or negative, depending upon the network conditions in which a firm is embedded. Our results suggest that a venture capital firm pursuing a more distinctive position needs to be involved in a highly embedded network to achieve high performance, and that a venture capital firm pursuing a less distinctive position needs to be involved in a sparsely connected network to achieve high performance.

Our findings also encourage managers to think more broadly about the competitive positioning 
of their firms. To successfully position a firm in a competitive environment, we suggest that merely selecting a distinctive set of products or processes is not enough. Competitive positioning also involves a consideration of complex interactions between firms in a social context where firms are more or less embedded. Such a social context exists within a network of inter-firm relationships that provide critical information and knowledge for business operations. Understanding the social context is an important task for managers who try to position their firms strategically in a competitive arena.

\section{Limitations and extensions}

Several limitations pertain to this study. Although we tried to conduct a longitudinal investigation, the timeframe of this research (1995-98) is short owing to the lack of reliable archival information on specific venture capital firm activity prior to 1995 (Gompers and Lerner, 1999) and the difficulty of obtaining complete venture capital firm board-of-director-backed IPO information after 1998. Given that we have only 4 years of data, we split the data into two periods of 2 years each, and used niche and network data in the first 2-year time period to predict venture capital firm performance outcomes in the second 2-year time period. It is certainly possible that alternative models could be created. For example, there may be a reverse causation model, whereby a venture capital firm's performance may affect its niche position as well as its network structure. However, given the limited data available, we are unable to test all possible alternative causal models. We chose our current research design because we are interested in predicting performance outcomes. As many scholars have suggested, IPO performance is a fundamental outcome to predict as venture capital firms heavily rely on IPOs to succeed (e.g., Black and Gilson, 1999; Gompers and Lerner, 1999; Huntsman and Hoban, 1980; Schilit, 1991). Our research does not rule out the possibility of other alternative causal models, but is an initial step toward understanding the complexity of intertwined relationships.

Another concern related to the short timeframe of this research is that possible idiosyncratic market conditions during this period may limit the generalizability of our findings to other time periods. To better understand the effects of recent dynamics on the venture capital industry, we spoke

Copyright @ 2004 John Wiley \& Sons, Ltd. with several industry experts. According to these experts, the key success factors required in the venture capital industry did not dramatically change between the mid-1990s and the year 2000. Anecdotal evidence, as provided by the majority of our interviewees, leads us to believe that the way in which venture capital firms conduct business and, thus, may differentiate themselves, especially in terms of product selection, has likewise not dramatically changed in terms of firms' ability to be relatively common or unusual. Thus, our independent variables do not seem to be affected by idiosyncratic market conditions during the timeframe of our research. With respect to the potential impact of market conditions on our dependent variable, we benchmarked IPO stock price to the NASDAQ Composite Index, and controlled for investment sentiment and uncertainty in our additional analyses. However, these controls are by no means comprehensive given the range of macroeconomic conditions that may have impacted our findings.

Another limitation is that we tested our theory and hypotheses in a specific industry, which may restrict external generalizability to other industries. Future studies that replicate our model using a larger sample covering similar project-based industries, such as construction, film, law, or music, as well as non-project-based industries, may enhance external validity. When exploring other industries, researchers may obtain enlightening results by examining resource distribution within the population, changes in concentration, and environmental conditions - characteristics that affect niche firms and their outcomes. Furthermore, we constructed a network of inter-firm relationships based on IPO data. Venture capital firms have other networks that our study does not measure, and the importance of these networks needs to be investigated. Other networks could be more or less meaningful to the venture capital firm compared to their co-investment relationships in IPOs. To study other venture capital firm networks such as referral, advice seeking, or friendship resources requires that we gather primary data and ensure a complete response from every single firm.

Future research may advance our understanding of the niche concept by examining how niches are formed and sustained. Certain resources and capabilities are required for firms to strategically obtain a niche position. Perhaps the resourcebased or dynamic capabilities view of the firm 
can provide a useful lens for researchers studying niche formation and sustainability. Researchers may examine whether the formation of a process niche requires more tacit knowledge than the formation of a product niche (Reed and DeFillippi, 1990) to explain why a process niche may sustain longer than a product niche. Researchers may also examine which kinds of firms are more likely to occupy certain types of niche.

To further extend our understanding of the niche-network-performance relationship, future research might explore how a niche may change over time, how niche changes may affect firm performance, and how a firm's niche and network co-evolve. Moreover, future research may explore antecedents of why certain social structures are formed, discover additional moderators or mediators to niche theory, and apply other theoretical perspectives to understanding firm performance. Many opportunities exist to deepen our understanding regarding how firms weigh alternatives, determine how to conduct business, and decide when to change how they conduct business.

\section{CONCLUSION}

This research enhances our understanding of how firms use niche and network structure to improve their performance. Based on data from the venture capital industry, the results show that a venture capital firm is more likely to reap economic gains from doing business in a niche when surrounded by other venture capital firms that are tightly linked in embedded relationships than when surrounded by other venture capital firms that are sparsely connected. The more a firm differentiates itself from other firms in terms of what product it offers, or how it operates, the more embedded its inter-firm network needs to be to positively affect its performance. The results of this study contribute to the organizational ecology and strategic management literatures by identifying different niche types and clarifying the niche-performance relationship. The results also contribute to social network research by showing the value (and the possible downside) of network embeddedness. Certainly, niche and network structure should be studied simultaneously; establishing a product or process niche alone is not enough to achieve superior performance. Managers are wise to thoughtfully consider their firm's position in an inter-firm network when crafting a niche strategy.

\section{ACKNOWLEDGEMENTS}

We would like to thank Don Bergh, Steve Borgatti, Denny Gioia, Don Hambrick, David Harrison, Martin Kilduff, Yasemin Kor, David Krackhardt, Chris Muscarella, Linda Tegarden, Linda Treviño, Klaus Weber, David Wagstaff, and two anonymous reviewers for their helpful comments and suggestions on earlier drafts of this manuscript. We are grateful to Ilya Lipkovich for helping with mathematical computations, Raman Kumar for assisting in programming and downloading CRSP data, and Nicola McCarthy for editing our manuscript. This research was partially supported by the Farrell Center for Entrepreneurship in the Smeal College of Business Administration at Penn State.

\section{REFERENCES}

Aiken LS, West SG. 1991. Multiple Regression: Testing and Interpreting Interactions. Sage: Newbury Park CA.

Baker WE, Obstfeld D. 1999. Social capital by design: structures, strategies, and institutional context. In Corporate Social Capital and Liability, Leenders RTAJ, Gabbay SM (eds). Kluwer: Norwell, MA; 88-105.

Barry CB, Muscarella CJ, Peavy JW III, Vetsuypens MR. 1990. The role of venture capital in the creation of public companies. Journal of Financial Economics 27: 447-471.

Baum JAC, Oliver C. 1996. Toward an institutional ecology of organizational founding. Academy of Management Journal 39: 1378-1427.

Black BS, Gilson RJ. 1999. Does venture capital require an active stock market? Bank of America Journal of Applied Corporate Finance 11: 36-48.

Bollen KA. 1989. Structural Equations with Latent Variables. Wiley: New York.

Brush CG, Chaganti R. 1999. Businesses without glamour? An analysis of resources on performance by size and age in small service and retail firms. Journal of Business Venturing 14: 233-257.

Burt RS. 1992. Structural Holes: The Social Structure of Competition. Harvard University Press: Cambridge, MA.

Carter R, Van Auken HE. 1994. Venture capital firms' preferences for projects in particular stages of development. Journal of Small Business Management 32: $60-73$.

Carroll GR. 1984. The specialist strategy. California Management Review 26: 126-137. 
Carroll GR. 1985. Concentration and specialization: dynamics of niche width in populations of organizations. American Journal of Sociology 90: 1262-1283.

Chatterjee S. 1998. Delivered desired outcomes efficiently: the creative key to competitive strategy. California Management Review 40: 78-95.

Coleman JS. 1990. Foundations of Social Theory. Belknap Press of Harvard University Press: Cambridge, MA.

Coleman JS. 1994. A rational choice perspective on economic sociology. In The Handbook of Economic Sociology, Smelser N, Swedberg R (eds). Princeton University Press: Princeton, NJ; 166-180.

Coleman JS, Katz E, Menzel H. 1966. Medical Innovation. Bobbs-Merrill: Indianapolis, IN.

Day GS. 1981. Strategic market analysis and definition: an integrated approach. Strategic Management Journal 2: 281-299.

Dyer JH, Nobeoka K. 2000. Creating and managing a high-performance knowledge-sharing network: the Toyota Case. Strategic Management Journal, Special Issue 21: 345-367.

Elton C. 1927. Animal Ecology. Sidgwick \& Jackson: London.

Freeman J. 1999. Venture capital as an economy of time. In Corporate Social Capital and Liability, Leenders RTAJ, Gabbay SM (eds). Kluwer: Norwell, MA; 460-479.

Fried VH, Hisrich RD. 1995. The venture capitalist: a relationship investor. California Management Review 37: 101-113.

Galbraith C, Schendel D. 1983. An empirical analysis of strategy types. Strategic Management Journal 4(2): $153-173$.

Gompers PA. 1994. The rise and fall of venture capital. Business and Economic History 23: 1-26.

Gompers PA, Lerner J. 1999. The Venture Capital Cycle. MIT Press: Cambridge, MA.

Gorman M, Sahlman WA. 1989. What do venture capitalists do? Journal of Business Venturing 4: 231-248.

Granovetter M. 1973. The strength of weak ties. American Journal of Sociology 78: 1360-1380.

Granovetter M. 1985. Economic action and social structure: the problem of embeddedness. American Journal of Sociology 78: 1360-1380.

Granovetter M. 1992. Problems of explanation in economic sociology. In Networks and Organizations: Structure, Form, and Action, Nohria N, Eccles RG (eds). Harvard Business School Press: Boston, MA; 25-56.

Gulati R. 1995. Does familiarity breed trust? The implications of repeated ties for contractual choice in alliances. Academy of Management Journal 38: $85-112$.

Gulati R. 1998. Alliances and networks. Strategic Management Journal, Special Issue 19(4): 293-317.

Gulati R, Nohria N, Zaheer A. 2000. Strategic networks. Strategic Management Journal, Special Issue 21(3): 203-215.
Gupta AK, Sapienza HJ. 1988. The pursuit of diversity by venture capital firms: antecedents and implications. In Frontiers of Entrepreneurship Research: Proceedings of the Eighth Annual Babson College Entrepreneurship Research Conference, Kirchhoff BA, Long WA, McMullan W, Vesper KH, Wetzel WE Jr (eds).Center for Entrepreneurial Studies, Babson College: Wellesley, MA; 290-302.

Gupta AK, Sapienza HJ. 1992. Determinants of venture capital firms' preferences regarding the industry diversity and geographic scope of their investments. Journal of Business Venturing 7: 347-362.

Hannan MT, Freeman J. 1977. The population ecology of organizations. American Journal of Sociology 82: 929-964.

Hansen MT. 1999. The search-transfer problem: the role of weak ties in sharing knowledge across organization subunits. Administrative Science Quarterly 44: $82-111$.

Harrigan KR. 1985. An application of clustering for strategic group analysis. Strategic Management Journal 6(1): 55-73.

Hoskisson RE, Hitt MA, Johnson RA, Moesel DD. 1993. Construct validity of an objective (entropy) categorical measure of diversification strategy. Strategic Management Journal 14(3): 215-235.

Huntsman B, Hoban JP Jr. 1980. Investment in new enterprise: some empirical observations on risk, return, and market structure. Financial Management 9: $44-51$.

Jain BA. 2001. Predictors of performance of venture capitalist-backed organizations. Journal of Business Research 52: 223-233.

Jones C, Hesterly WS, Fladmoe-Lindquist K, Borgatti SP. 1998. Professional service constellations: how strategies and capabilities influence collaborative stability and change. Organization Science 9: 396-410.

Kendall M, Stuart A. 1979. The Advanced Theory of Statistics. Inference and Relationship, Vol. 2. Hafner: Riverside, NJ.

Krackhardt D. 1992. The strength of strong ties: the importance of philos in organizations. In Networks and Organizations: Structure, Form, and Action, Nohria N, Eccles RG (eds). Harvard Business School Press: Boston, MA; 216-239.

Lacity M, Jansen MA. 1994. Understanding qualitative data: a framework of text analysis methods. Journal of Management Information Systems 11: 137-166.

Lawless MW, Anderson PC. 1996. Generational technological change: effects of innovation and local rivalry on performance. Academy of Management Journal 39: 1185-1217.

Lerner J. 1994a. A note on the venture capital industry. Harvard Business School Case Number 9-295-065. Harvard Business School: Boston, MA.

Lerner J. 1994b. The syndication of venture capital investments. Financial Management 23: 16-27.

Lerner J. 1994c. Venture capitalists and the decision to go public. Journal of Financial Economics 35: 293-316.

Lerner J. 1995. Venture capitalists and the oversight of private firms. Journal of Finance 50: 301-318. 
Liles RR. 1977. Sustaining the Venture Capital Firm. Harvard Business School, Division of Research: Boston, MA.

Lin N. 1999. Building a network theory of social capital. Connections 22: 28-51.

Lindsey JK. 1995. Modeling Frequency and Count Data. Oxford University Press: New York.

MacMillan IC, Kulow DM, Khoylian R. 1989. Venture capitalists' involvement in their investments: extent and performance. Journal of Business Venturing 4: 27-47.

Markides C. 1998. Strategic innovation in established companies. Sloan Management Review 39: 31-42.

McPherson M. 1983. An ecology of affiliation. American Sociological Review 48: 519-532.

Megginson WL, Weiss KA. 1991. Venture capital certification in initial public offerings. Journal of Finance 46: 879-903.

Morrison AJ, Roth K. 1992. A taxonomy of businesslevel strategies in global industries. Strategic Management Journal 13(6): 399-417.

Nahapiet J, Ghoshal S. 1998. Social capital, intellectual capital, and the organizational advantage. Academy of Management Review 23: 242-266.

Nelson RE. 1989. The strength of strong ties: social networks and intergroup conflict in organizations. Academy of Management Journal 32: 377-401.

Norton E, Tenenbaum BH. 1993. Specialization versus diversification as a venture capital investment strategy. Journal of Business Venturing 8: 431-442.

Pedhazur EJ, Schmelkin LP. 1991. Measurement, Design, and Analysis: An Integrated Approach. Erlbaum: Hillsdale, NJ.

Podolny JM. 1994. Market uncertainty and the social character of economic exchange. Administrative Science Quarterly 39: 458-483.

Podolny JM, Baron JN. 1997. Resources and relationships: social networks and mobility in the workplace. American Sociological Review 62: 673-693.

Podolny JM, Stuart TE, Hannan MT. 1996. Networks, knowledge, and niches: competition in the worldwide semiconductor industry, 1984-1991. American Journal of Sociology 102: 659-689.

Porter ME. 1980. Competitive Strategy: Techniques for Analyzing Industries and Competitors. Free Press: New York.

Porter ME. 1996. What is strategy? Harvard Business Review 74(6): 61-78.

Powell WW. 1990. Neither market nor hierarchy: network forms of organization. In Research in Organizational Behavior, Vol. 12, Cummings LL, Shaw B (eds). JAI Press: Greenwich, CT; 295-336.

Reed R, DeFillippi RJ. 1990. Causal ambiguity, barriers to imitation, and sustainable competitive advantage. Academy of Management Review 15: 88-102.

Ricklefs RE. 1979. Ecology. Chiron Press: New York.

Ritter JR. 1991. The long-run performance of initial public offerings. Journal of Finance 46: 3-27.

Robinson SL, O'Leary-Kelly AM. 1998. Monkey see, monkey do: the influence of work groups on the antisocial behavior of employees. Academy of Management Journal 41: 658-672.
Rowley T, Behrens D, Krackhardt D. 2000. Redundant governance structures: an analysis of structural and relational embeddedness in the steel and semiconductor industries. Strategic Management Journal 21(3): 369-386.

Ruhnka JC, Young JE. 1987. A venture capital model of the development process for new ventures. Journal of Business Venturing 2: 167-184.

Ruhnka JC, Young JE. 1991. Some hypotheses about risk in venture capital investing. Journal of Business Venturing 6: 115-133.

Sahlman W. 1990. The structure and governance of venture capital organizations. Journal of Financial Economics 27: 473-524.

Schilit WK. 1991. Dream Makers and Deal Breakers: Inside the Venture Capital Industry. Prentice-Hall: Englewood Cliffs, NJ.

Scott J. 2000. Social Network Analysis: A Handbook (2nd edn). Sage: Thousand Oaks, CA.

STATA. 1997. Reference Manual, Release 5. STATA Press: College Station, TX.

Steele JM. 1989. Models for managing secrets. Management Science 35: 240-248.

Steier L, Greenwood R. 1995. Venture capitalist relationships in the deal structuring and post-investment stages of new firm creation. Journal of Management Studies 32: $337-357$.

Stuart TE. 1998. Network positions and propensities to collaborate: an investigation of strategic alliance formation in a high-technology industry. Administrative Science Quarterly 43: 668-698.

Tsai W, Ghoshal S. 1998. Social capital and value creation: the role of intra-firm networks. Academy of Management Journal 41: 464-476.

Tsai W. 2000. Social capital, strategic relatedness, and the formation of intra-organizational strategic linkages. Strategic Management Journal 21(9): 925-939.

Tsai W. 2001. Knowledge transfer in intra-organizational networks: effects of network position and absorptive capacity on business unit innovation and performance. Academy of Management Journal 44: 996-1004.

Tsai W. 2002. Social structure of 'competition' within a multiunit organization: coordination, competition, and intra-organizational knowledge sharing. Organization Science 13: 179-190.

Tyebjee TT, Bruno AV. 1984a. A model of venture capitalist investment activity. Management Science 30: $1051-1066$.

Tyebjee TT, Bruno AV. 1984b. Venture capital: investor and investee perspectives. Technovation 2: 185-208.

Uzzi B. 1996. The sources and consequences of embeddedness for the economic performance of organizations: the network effect. American Sociological Review 61: 674-698.

Uzzi B. 1997. Social structure and competition in interfirm networks: the paradox of embeddedness. Administrative Science Quarterly 42: 35-67. 


\section{APPENDIX 1: FORMULA USED TO COMPUTE THE DEPENDENT VARIABLE: FIRM PERFORMANCE}

Firm performance $=$ Number of successful IPOs Success $=1$, when Benchmarked_return ${ }_{i, 12}>0$ where:

$$
\begin{aligned}
& \text { Benchmarked_return }_{i, t} \\
& =\left\{\left[\prod_{\tau=T 0}^{T t}\left(1+R_{i, \tau}\right)\right]\right\}-\left\{\left[\prod_{\tau=T 0}^{T t}\left(1+R_{\mathrm{m}, \tau}\right)\right]\right\}
\end{aligned}
$$

Benchmarked_return $_{i, t}$ is the abnormal stock price performance of the new issue, $i$, from the offer date to the end of month $t$

$i$ is the index of stocks

$t$ is the index of months from month 1 to 12 , where a month is a successive 21-trading-day period following Ritter (1991)

$\tau$ (tau) is the index of days

$T_{o}$ is the first aftermarket return day in CRSP within 6 days after the offering date

$T_{t}$ is the last day of month $t$ (i.e., days $22,43,64$, $85,106,127,148,169,190,211,232,253)$

$R_{i, \tau}=$ defined by 'RET()' in the CRSP tapes $=\left(P_{i, \tau}-P_{i, \tau-1}+f_{i, \tau}+D I V_{i, \tau}\right) / P_{i, \tau-1}$

$f_{i, \tau}=$ price adjustment factor for stock $i$

$R_{m, \tau}=$ (NASDAQIndex $_{i, \tau}-$ NASDAQ-

Index $\left._{i, \tau-1}\right) /$ NASDAQIndex $x_{i, \tau-1}$

$P=$ stock price

$D I V=$ stock dividend

\section{APPENDIX 2: FORMULA USED TO COMPUTE INDEPENDENT VARIABLE: OPERATIONAL NICHE}

Based on the non-overlap intensity measure used by Baum and Oliver (1996), a venture capital firm's operational niche is computed as $f_{i}=n-$ $d_{i}$ where:

$f$ is a vector of non-overlap intensities for a venture capital firm

Each venture capital firm $F_{i}(I=1, \ldots, n)$ is associated with its profile of $m$ binary indicators $x_{i j}=\{0,1\}, j=1, \ldots, m$, where a 1 means the venture capital firm operates in one of the following stages, and a 0 means it does not: Research and Development, Seed, Start-up, First Stage, Second Stage, Mezzanine, Bridge, Acquisition, Leveraged Buy-out, Management Buy-out, Recapitalization, and/or Special Financing.

Niches are defined as distinct profiles $\left\{x_{i j}, j=\right.$ $1, \ldots, m\}$. Let the number of venture capital firms in each niche $k$ be $n_{k}$

The total number of venture capital firms, $n$, is partitioned as $n=\sum_{k=1}^{l} n_{k}$, where $l$ is the number of distinct niches

The overlap density for the $i$ th niche is computed as $d_{i}=n_{i}+\sum_{j \neq i} n_{j} w_{i j}$

The niche overlap weight $w_{i j}$ for niches $i$ and $j$ are computed as follows:

$$
\begin{aligned}
w_{i j}= & \frac{\#\left\{x_{i k}=1 \text { and } x_{j k}=1, k=1, . ., m\right\}}{\#\left\{x_{i k}=1, k=1, . ., m\right\}} \\
& \left(\text { Notice that } w_{i j} \neq w_{j i}\right)
\end{aligned}
$$


Reproduced with permission of the copyright owner. Further reproduction prohibited without permission. 